\title{
Allergic rhinitis and genetic components: focus on Toll-like receptors (TLRs) gene polymorphism
}

This article was published in the following Dove Press journal:

The Application of Clinical Genetics

15 November 2010

Number of times this article has been viewed

\author{
Zhiwei Gao' \\ Donna C Rennie ${ }^{2}$ \\ Ambikaipakan Senthilselvan \\ 'Department of Public Health \\ Sciences, School of Public Health, \\ University of Alberta, Edmonton, \\ Alberta, Canada; ${ }^{2}$ College of Nursing \\ and Canadian Centre for Health \\ and Agricultural Safety, University \\ of Saskatchewan, Saskatoon, \\ Saskatchewan, Canada
}

\begin{abstract}
Allergic rhinitis represents a global health issue affecting $10 \%$ to $25 \%$ of the population worldwide. Over the years, studies have found that allergic diseases, including allergic rhinitis, are associated with immunological responses to antigens driven by a Th2-mediated immune response. Because Toll-like receptors (TLRs) are involved in both innate and adaptive immune responses to a broad variety of antigens, the association between polymorphisms of TLRs and allergic diseases has been the focus in many animal and human studies. Although the etiology of allergic rhinitis is still unknown, extensive research over the years has confirmed that the underlying causes of allergic diseases are due to many genetic and environmental factors, along with the interactions among them, which include gene-environment, gene-gene, and environment-environment interactions. Currently, there is great inconsistency among studies mainly due to differences in genetic background and unique gene-environment interactions. This paper reviews studies focusing on the association between TLR polymorphisms and allergic diseases, including allergic rhinitis, which would help researchers better understand the role of TLR polymorphisms in the development of allergic rhinitis, and ultimately lead to more efficient therapeutic interventions being developed.
\end{abstract}

Keywords: allergic rhinitis, allergic diseases, Toll-like receptors

\section{Introduction}

Allergic rhinitis represents a global health issue affecting $10 \%$ to $25 \%$ of the population worldwide, with increasing prevalence during the last decade. ${ }^{1}$ The socioeconomic impact of allergic rhinitis is substantial, which includes not only the costs of disease management but also indirect costs such as reduced productivity and absenteeism from work, and the cost of treating conditions associated with allergic rhinitis, such as asthma, sinusitis, otitis media, nasal polyps, and lower respiratory tract infection. ${ }^{2}$ Allergic diseases rank sixth among leading chronic diseases in the United States. ${ }^{3}$ Extensive research in the last 2 decades has confirmed that the underlining causes of allergic diseases are associated with not only many genetic and environmental factors but also the interactions among them, which include gene-gene, environment-environment, and gene-environment interactions. Over the years, more than 100 genes have been linked to atopic diseases, with no single gene contributing to more than $5 \%$ of the observed phenotype. ${ }^{4}$ The 'hygiene hypothesis', proposed by Strachan in 1989, has been used to explain the increase in allergic diseases reported in the developed countries. ${ }^{5}$ According to this hypothesis, allergic diseases are caused by immunological responses to antigens driven by a Th2-mediated immune response, which is usually downregulated by a Th1-mediated 
immune response. Insufficient stimulation on the Th1 arm due to the lack of exposure to specific infections, or perhaps endotoxin during early life, could lead to an overactive Th2 arm, which is associated with the development of allergic diseases. ${ }^{6} \mathrm{~A}$ family of pattern recognition receptors (PRRs), including Toll-like receptors (TLRs), have become the focus over recent years because they are directly involved in human innate immune recognition and regulation of proper adaptive immune responses. The innate approach to microbial recognition by PRRs fundamentally differs from the developmental process of the adaptive immune system, in which T and B lymphocytes are involved. Adaptive immunity is not inherited and is 'trained' over time. ${ }^{7}$ Activation of antigen-specific adaptive immunity needs information about the origin of the antigen and the type of response to be induced. All these actions require the involvement of the innate immune system. Improper responses from innate immunity may lead to attacking self antigens, such as apoptotic cells, or harmless persistent environmental antigens. ${ }^{8}$ The important role of TLRs in both innate and adaptive immunity has drawn extensively from studies on the effects of their structures and genetic variations on allergic diseases. In this review, we aim to summarize our current knowledge on TLRs, polymorphisms of TLR genes, and their roles in the development of allergic diseases, with the focus on allergic rhinitis.

\section{TLRs reorganization and activation}

TLRs are a type of pattern recognition receptors and must be able to distinguish between 'self', such as apoptotic cells generated by normal tissue, and 'invaders', such as virus and bacteria. The Toll receptor was first found in the fruit fly, Drosophila melanogaster, with its essential role in activating the synthesis of antimicrobial peptides against fungal infection. ${ }^{9}$ The first human TLR was reported in 1994. ${ }^{10}$ Since then, 10 TLRs (TLR1 to TLR10) have been identified in the human genome. These 10 TLRs are located on 4 autosomes (chromosome 1, 3, 4, and 9) and chromosome X, and are not evenly distributed across these chromosomes. Five TLRs are located on chromosome 4, with TLR1, TLR6, and TLR10 on $\mathrm{p}$ arm and TLR2 and TLR3 on $\mathrm{q}$ arm. TLR7 and TLR8 are located on chromosome $\mathrm{X}$ p22. TLR4, TLR5, and TLR9 are located on chromosome 9,1 , and 3, respectively. Based on their cellular localization and PAMP ligands, the 10 human TLRs can be divided into 2 groups. ${ }^{11}$ The first group of TLRs (TLR1, TLR2, TLR4, TLR5 and TLR6) recognizes mainly microbial membrane components such as lipids, lipopolysaccharides (LPS), and lipoproteins. The second group of TLRs (TLR3, TLR7, TLR8, and TLR9) recognizes microbial nucleic acids and is expressed exclusively in intracellular vesicles such as endosomes, lysosomes, and endolysosomes. The ligands to TLR10 in humans have not yet been identified. ${ }^{12}$ TLRs are type I transmembrane proteins with leucine-rich repeats, such as ectodomain, which mediates the recognition of PAMPs; transmembrane domains; and intracellular Tollinterleukin 1 (IL-1) receptor (TIR) domains, which are responsible for downstream signal transduction. ${ }^{13} \mathrm{~A}$ unique feature of TLRs is that they recognize a broad diversity of ligands, which include microbial cell wall components (endotoxin from gram-negative bacteria) by TLR4, peptidoglycan and lipoproteins (from gram-positive bacteria) by TLR 2 in combination with TLR 1 or TLR6, ${ }^{14}$ bacterial flagellin by TLR5, ${ }^{15}$ unmethylated CpG sequences (from microbial DNA) by TLR9, ${ }^{16}$ viral double-stranded RNA by TLR $3,{ }^{17}$ and viral single-stranded RNA by TLR7 and TLR $8 .{ }^{18}$ Other genes, such as NOD1 and NOD2, have been found to be involved in signaling initiated by PRRs, ${ }^{19,20}$ but their roles relative to TLR-dependent pathways are still unknown.

TLRs recognize constituents of microbial cell walls or pathogen-specific nucleic acids. Most of the molecules recognized by TLRs are essential to the basic survival of microbes or viruses (integrity, function, or replication), and therefore microbial alterations would not be able to escape detection by TLRs. ${ }^{21}$ Once microbes penetrate an epithelial barrier, they will be targeted by tissue macrophages, mast cells, and immature dendritic cells. Stimulation of the TLRs on these cells leads to initiation of innate immune response, which includes recruiting immune cells to sites of infection through cytokines, activating the complement cascade and removal of foreign substances by specialized white blood cells, and activating the adaptive immune system through the antigen presentation process. The antigen presentation process begins with the engulfing of allergens by antigenpresenting cells (APCs), such as dendritic cells. Following digestion, APCs present fragments of allergen to allergenspecific $\mathrm{CD}^{+} \mathrm{T}$ cells. CD4 ${ }^{+}$cells secrete Th2 cytokines, such as IL-4 and IL-5. ${ }^{22,23}$ Although the innate immune response is an immediate defence against infection, it is less efficient (not antigen specific), and does not last long. The adaptive immune response has the ability to recognize and remember specific pathogens, and to mount stronger attacks upon re-exposure. 


\section{TLRs signaling pathway of immune response}

The signals from TLRs have to be tightly controlled and their overactivation leads to inflammatory diseases..$^{24}$ Although the number of TLRs is limited, they have the capacity to recognize the wide spectrum of ligands. Studies have shown that TLRs, specificity results from cooperation between TLRs by forming heterodimers or homodimers. ${ }^{25}$ The heterodimers of TLR2 and TLR6 lead to the reorganization of peptidoglycan (a gram-positive pathogen) and activation of tumor necrosis factor-alpha (TNF- $\alpha$ ) in the production in macrophages. TLR2 alone recognizes another component, bacterial lipopeptide. TLR4 invokes immune responses by forming a homodimer. These TLR dimers are in a low-affinity complex before ligand binding. The binding of specific ligands leads to a structural reorganization of the cytosolic TIR domains, which is used as a signaling platform for adaptor recruitment. ${ }^{26}$

TLRs may also depend on co-receptors for full ligand sensitivity, such as in the case of TLR4's recognition of LPS, which requires MD-2. CD14 and LPS binding protein (LBP) is known to facilitate the presentation of LPS to MD-2. ${ }^{27,28}$ As well, TLRs need to recruit adaptor proteins to propagate signals within cytoplasm of cells, which ultimately leads to the activation of transcription factors, such as nuclear factor-kB (NF-kB) and members of the interferon (IFN)regulatory factor (IRF) family. Detailed information on all TLR signaling pathways and 5 adaptor proteins of the TIR domain of TLRs has been well summarized and reviewed in other papers. ${ }^{29}$

\section{TLR SNPs and allergic diseases}

TLRs are highly polymorphic and play an important role in both innate and adaptive immunity ${ }^{31}$ It is not surprising that single nucleotide polymorphisms (SNPs) of these genes would influence the development of allergic diseases. ${ }^{32}$ A total of 909 SNPs on 10 human TLRs are listed on the National Center for Biotechnology Information (NCBI) website (http://www.ncbi.nlm.nih.gov; accessed on July 06, 2010). As described on the NCBI website, the majority of the studies on the function of TLRs have focused on TLR2, TLR4, and TLR9. In total, 17 out of the 909 SNPs have been associated with allergic diseases. These 17 SNPs comprise 2 on TLR1, 4 on TLR2, 2 on TLR4, 3 on TLR6, 1 on TLR7, 2 on TLR8, 1 on TLR9, and 2 on TLR10. Although expressions of TLR3 and TLR5 have been linked with allergic rhinitis ${ }^{34}$ and asthma, ${ }^{36}$ none of the SNPs on
TLR3 and TLR5 has been shown to be associated with allergic diseases.

\section{Prevalence of TLR SNPs associated with allergic diseases}

Because allele frequency of one gene can vary between different populations, minor allele frequencies of TLR SNPs, which have been associated with allergic diseases including allergic rhinitis, were stratified by ethnic groups and patient and comparison groups, in Table 1.

As shown in Table 1, 2 SNPs on TLR1 (rs5743595, rs4833095) have been associated with atopic asthma. The first SNP (rs5743595) is located in the intron region of TLR1 and the second (rs4833095), a missense mutation, is located in the coding region of TLR1. The HapMap study (http://www.genecards.org; accessed on July 06, 2010) showed that the prevalence of minor allele $\mathrm{T}$ in rs4833095 in African American, Chinese, and Japanese populations, and $\mathrm{C}$ allele in Caucasian populations, was $13 \%, 31 \%, 36 \%$, and $30 \%$, respectively. For the SNP rs5743595, prevalence of the minor allele $\mathrm{C}$ in Caucasian, $\mathrm{G}$ in Chinese, and $\mathrm{A}$ in Japanese populations was $27 \%, 43 \%$, and $47 \%$, respectively, in the HapMap. A population study of 1872 German children aged 9 to 11 years showed that the prevalence of the minor $\mathrm{C}$ allele in rs5743595 and $\mathrm{T}$ allele in rs4833095 was $17 \%$ and $19 \%$, respectively. ${ }^{37}$

There are 4 SNPs on TLR2 that have been associated with allergic rhinitis, asthma, and atopy (Table 1). Three of these (rs3804099, rs3804100, and rs5743708) are in the coding region, and the fourth (rs4696480) is located in the intron region of TLR2. The HapMap study showed that for rs 3804099 , the prevalence of minor allele $\mathrm{C}$ was $44 \%$ in Caucasian, 36\% in Chinese, and 28\% in Japanese populations, and the prevalence of T allele was $37 \%$ in African American populations. The prevalence of $\mathrm{C}$ allele in rs 3804100 was $5 \%$ in Caucasian, $7 \%$ in African American, $33 \%$ in Chinese, and $23 \%$ in Japanese populations, and the prevalence of A allele in rs5743708 and rs 4696480 was less than 5\% in the HapMap. A case-control study of 440 adults with allergic rhinitis as cases and 528 healthy adults as controls from Korea showed that the prevalence of minor allele C in rs3804099 and rs 3804100 was $32 \%$ and $31 \%$, respectively, in cases, and $31 \%$ and $29 \%$, respectively, in controls. ${ }^{38}$ Another case-control study of 108 children with allergic asthma and 496 controls from Norway showed that the prevalence of minor allele $\mathrm{C}$ in rs 3804100 was $8 \%$ in cases and $11 \%$ in controls. ${ }^{39}$ A cross-sectional study of 3099 German children 
Table I Toll-like receptor single nucleotide polymorphisms significantly associated with allergic diseases including allergic rhinitis from different populations

\begin{tabular}{|c|c|c|c|c|c|c|c|c|c|}
\hline \multirow[t]{2}{*}{ TLR } & \multirow{2}{*}{$\begin{array}{l}\text { Ethnic } \\
\text { group }\end{array}$} & \multirow{2}{*}{$\begin{array}{l}\text { Design } \\
\text { (sample size) }\end{array}$} & \multirow{2}{*}{$\begin{array}{l}\text { Age } \\
\text { (years) }\end{array}$} & \multirow[t]{2}{*}{ rs } & \multirow[t]{2}{*}{ Allele } & \multirow{2}{*}{$\begin{array}{l}\text { Minor allele } \\
\text { frequency (\%) }\end{array}$} & \multicolumn{3}{|c|}{ Allergic diseases } \\
\hline & & & & & & & Inheritance & $\begin{array}{l}\text { Allergic } \\
\text { rhinitis }\end{array}$ & Others \\
\hline \multirow[t]{2}{*}{ TLRI } & German $^{37}$ & Case-control & $9-11$ & rs4833095 & $\mathrm{C} / \mathrm{T}$ & 19 & Dominant & & Atopic asthma \\
\hline & & $\begin{array}{l}\text { (cases: } 624, \\
\text { controls: } 1,248 \text { ) }\end{array}$ & & rs5743595 & $\mathrm{T} / \mathrm{C}$ & 17 & Dominant & & Atopic asthma \\
\hline \multirow[t]{6}{*}{ TLR2 } & German $^{40}$ & $\begin{array}{l}\text { Cross-sectional } \\
(\mathrm{n}=3099)\end{array}$ & $9-11$ & rs5743708 & $\mathrm{G} / \mathrm{A}$ & 3 & Dominant & & Atopy \\
\hline & $\begin{array}{l}\text { German/ } \\
\text { Austrian }^{41}\end{array}$ & $\begin{array}{l}\text { Cross-sectional } \\
(\mathrm{n}=609)\end{array}$ & $6-13$ & rs4696480 & $\mathrm{A} / \mathrm{T}$ & 49.7 & Dominant & Yes $^{\mathrm{a}}$ & $\begin{array}{l}\text { Atopy'; } \\
\text { asthma }^{\text {a }}\end{array}$ \\
\hline & Korean $^{38}$ & $\begin{array}{l}\text { Case-control } \\
\text { (cases: } 440, \\
\text { control: } 528 \text { ) }\end{array}$ & adults & rs3804099 & $\mathrm{T} / \mathrm{C}$ & $\begin{array}{l}\text { Cases: } 32 \\
\text { Controls: } 31\end{array}$ & $\begin{array}{l}\text { Haplotype } \\
\text { (C-C) }\end{array}$ & Yes & Atopic asthma \\
\hline & & & & rs3804I00 & $\mathrm{T} / \mathrm{C}$ & Cases: 31 & & & \\
\hline & & & & & & Controls: 29 & & & \\
\hline & Norwegian $^{39}$ & $\begin{array}{l}\text { Case-control } \\
\text { (cases: } 108, \\
\text { controls: } 496 \text { ) }\end{array}$ & children & rs3804I00 & $\mathrm{T} / \mathrm{C}$ & $\begin{array}{l}\text { Cases: } 8 \\
\text { Controls: II }\end{array}$ & Dominant & & Atopic asthma \\
\hline \multirow[t]{5}{*}{ TLR4 } & Canadian $^{42}$ & $\begin{array}{l}\text { Cross-sectional } \\
(n=9 \mid 5)\end{array}$ & adults & rs4986790 & $\mathrm{A} / \mathrm{G}$ & 5 & Dominant & Yes & Atopy ${ }^{b}$ \\
\hline & & & & rs498679| & $\mathrm{C} / \mathrm{T}$ & 4.7 & & & \\
\hline & Turkish $^{43}$ & $\begin{array}{l}\text { Cross-sectional } \\
(n=613)\end{array}$ & $6-18$ & rs4986790 & $\mathrm{A} / \mathrm{G}$ & 5.1 & Dominant & & Atopic asthma \\
\hline & & & & rs498679| & $\mathrm{C} / \mathrm{T}$ & 5.1 & Dominant & & \\
\hline & Swedish ${ }^{44}$ & $\begin{array}{l}\text { Cross-sectional } \\
(\mathrm{n}=|| \mid 5)\end{array}$ & $8-14$ & rs4986790 & $\mathrm{A} / \mathrm{G}$ & 9.6 & Dominant & & Atopic asthma \\
\hline \multirow[t]{4}{*}{ TLR6 } & German $^{37}$ & Case-control & $9-11$ & rs5743789 & $\mathrm{T} / \mathrm{A}$ & 18 & Dominant & & Atopic asthma \\
\hline & & $\begin{array}{l}\text { (cases: 624, } \\
\text { controls: 1248) }\end{array}$ & & rs5743810 & $\mathrm{C} / \mathrm{T}$ & 40 & Dominant & & Atopic asthma \\
\hline & German $^{45}$ & $\begin{array}{l}\text { Case-control } \\
\text { (cases: } 132, \\
\text { controls: } 212 \text { ) }\end{array}$ & $\begin{array}{l}2-15 \\
22-87\end{array}$ & rs57438I0 & $\mathrm{C} / \mathrm{T}$ & $\begin{array}{l}\text { Cases: } 49 \\
\text { Controls: } 40\end{array}$ & Dominant & & Atopic asthma \\
\hline & Chinese $^{46}$ & $\begin{array}{l}\text { Case-control } \\
\text { (cases: } 318 ; \\
\text { controls: } 352 \text { ) }\end{array}$ & $16-74$ & rs2381289 & $\mathrm{C} / \mathrm{T}$ & $\begin{array}{l}\text { Cases: } 48 \\
\text { Controls: } 41\end{array}$ & Dominant & $Y_{e s}^{d}$ & \\
\hline TLR7 & Danish $^{47}$ & $\begin{array}{l}\text { Cross-sectional } \\
\text { (Samples A: I35, } \\
\text { B: } 100 \text { families) }\end{array}$ & $15-45$ & rs 179008 & $\mathrm{~A} / \mathrm{T}$ & $\begin{array}{l}\text { Sample A: } 24 \\
\text { Sample B: } 21\end{array}$ & $\begin{array}{l}\text { Recessive and } \\
\text { additive }\end{array}$ & $Y_{e s}{ }^{e}$ & Atopy $^{b}$ \\
\hline \multirow[t]{2}{*}{ TLR8 } & Danish $^{47}$ & $\begin{array}{l}\text { Cross-sectional } \\
\text { (Samples A: I35, } \\
\text { B: } 100 \text { families) }\end{array}$ & $15-45$ & rs2407992 & $\mathrm{G} / \mathrm{C}$ & $\begin{array}{l}\text { Sample A: } 42 \\
\text { Sample B: } 38\end{array}$ & $\begin{array}{l}\text { Recessive and } \\
\text { additive }\end{array}$ & $Y_{e s}{ }^{e}$ & $\begin{array}{l}\text { Atopy }^{\mathrm{b}} ; \\
\text { dermatitis }^{\mathrm{b}}\end{array}$ \\
\hline & & & & rs5741883 & $\mathrm{C} / \mathrm{T}$ & $\begin{array}{l}\text { Sample A: } 25 \\
\text { Sample B: } 20\end{array}$ & Recessive & $Y_{e s}^{c}$ & \\
\hline TLR9 & German $^{48}$ & $\begin{array}{l}\text { Cross-sectional } \\
\text { and case-control } \\
(\mathrm{n}=483 \\
\text { cases: } 274, \\
\text { controls: } 252)\end{array}$ & trios & rs5743836 & $\mathrm{T} / \mathrm{C}$ & $\begin{array}{l}\text { Cases: I3 } \\
\text { Controls: II }\end{array}$ & TDT & & Atopic eczema \\
\hline \multirow[t]{2}{*}{ TLRIO } & German $^{37}$ & $\begin{array}{l}\text { Case-control } \\
\text { (cases: } 624, \\
\text { controls: } 1248 \text { ) }\end{array}$ & $9-11$ & rs4I29009 & $\mathrm{A} / \mathrm{G}$ & 16 & Dominant & & Atopic asthma \\
\hline & Chinese $^{46}$ & $\begin{array}{l}\text { Case-control } \\
\text { (cases: } 318, \\
\text { controls: } 352 \text { ) }\end{array}$ & $16-74$ & rsl|46665I & $\mathrm{G} / \mathrm{A}$ & $\begin{array}{l}\text { Cases: } 7 \\
\text { Controls: } 9\end{array}$ & Dominant & Yes $^{d}$ & \\
\hline
\end{tabular}

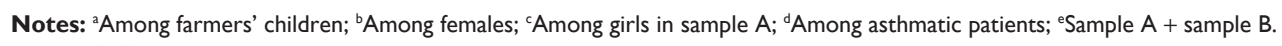

Abbreviation: TDT, transmission disequilibrium test. 
aged 9 to 11 years showed that the prevalence of minor allele $\mathrm{A}$ in rs5743708 was 3\%. ${ }^{40}$ Another cross-sectional study of 609 children aged 6 to 11 years from Germany and Austria showed that the prevalence of minor allele $\mathrm{T}$ in rs4696480 was 52\% among children living on farms and $49 \%$ among those not living on farms. ${ }^{41}$

As shown in Table 1, 2 SNPs (rs4986790 and rs4986791) of TLR4 have been associated with allergic rhinitis, atopy, and atopic asthma. Both SNPs are located in the coding region of TLR4 and cause missense mutation. The HapMap study showed that the prevalence of minor allele $\mathrm{G}$ in rs4986790 and $\mathrm{T}$ allele in rs4886791 was about 3\% in Caucasian and African American populations. A study of 915 university students from Saskatchewan, Canada showed that the prevalence of minor allele $\mathrm{G}$ in rs4986790 and $\mathrm{T}$ in rs4986791 was $5 \%$ and $4.7 \%$, respectively. ${ }^{42}$ A study of 613 asthma patients aged 6 to 18 years from Turkey showed the prevalence of minor allele $\mathrm{G}$ in rs4986790 and $\mathrm{T}$ in rs4986791 was $5.1 \% .{ }^{43}$ A study of 115 children aged 8 to 14 years from Sweden showed that the prevalence of minor allele $\mathrm{G}$ in rs4986790 was $9.6 \%{ }^{44}$

Three SNPs on TLR6 (rs5743789, rs5743810, and rs2381289) have been shown to be associated with allergic rhinitis and atopic asthma (Table 1). Two SNPs (rs5743789 and rs2381289) are located in the promoter region and the second SNP, rs57438100, is located in the coding region of TLR6. The HapMap study showed that the prevalence of minor allele A in rs5743789 was 4.3\% in African American, $15 \%$ in Caucasian, and $31 \%$ in Asian populations. The prevalence of T allele in rs 2381289 was $22 \%$ in African American population and $41 \%$ in Caucasian and $48 \%$ in Asian population. The prevalence of $\mathrm{T}$ allele in rs5743810 was $41 \%$ in Caucasian in the HapMap. A study of 1872 children aged 9 to 11 years from Germany showed that the prevalence of minor allele $\mathrm{A}$ in rs5743789 and $\mathrm{T}$ in rs5743810 was 18\% and $40 \%$, respectively. ${ }^{37} \mathrm{~A}$ case-control study of 132 children aged 2 to 15 years with asthma and 212 healthy controls from Germany showed that the prevalence of minor allele $\mathrm{T}$ in rs 5743810 was $49 \%$ in cases and $40 \%$ in controls. ${ }^{45}$ Another case-control study from China (318 asthmatic cases and 352 nonasthmatic controls) showed that the prevalence of minor allele $\mathrm{T}$ in rs 2381289 was $48 \%$ in cases and $41 \%$ in controls. ${ }^{46}$

One SNP on TLR7 (rs179008) and 2 SNPs on TLR8 (rs5741883 and rs2407992) have been associated with allergic rhinitis, atopy, and allergic dermatitis (Table 1). ${ }^{47}$ Two of these SNPs, rs179008 and rs2407992, are located in the coding regions of TLR7, the first one being a missense mutation and the second being synonymous, whereas rs5741883 is intergenic. The HapMap study showed that the prevalence of minor allele $\mathrm{G}$ in rs 2407992 was 4\% in African American, $18 \%$ in Chinese, $20 \%$ in Japanese, and 35\% C allele in Caucasian populations. The prevalence of $\mathrm{T}$ allele in rs 179008 was $16 \%$ in Caucasian and 19\% in African American populations and the prevalence of T allele in rs5741883 was 20\% in Caucasian populations, $48 \%$ in African American populations, and less than 5\% in Asian populations in the HapMap. A study of 2 family samples from Demark showed that the prevalence of minor allele $\mathrm{T}$ in rs 179008 was $21 \%$ and $24 \%$, $\mathrm{C}$ in rs 2407992 was $38 \%$ and $42 \%$, and $\mathrm{T}$ in rs 5741883 was $20 \%$ and $25 \%$ in the 2 samples, respectively. ${ }^{47}$

The SNP (rs5743836) on TLR9 has been associated with atopic eczema. The HapMap study showed that the prevalence of C allele on the SNP of rs5743836 was $16 \%$ in Caucasian, 25\% in African American, and 3\% in Asian populations. Novak et al reported in a case-control study from Germany (274 atopic eczema cases and 252 controls) that the prevalence of minor allele $\mathrm{C}$ in rs5743836 was $13 \%$ in cases and $11 \%$ in controls. ${ }^{48}$

Two SNPs in TLR10 (rs4129009 and rs11466651) have been associated with allergic rhinitis or atopic asthma. Both SNPs are located in the coding region of TLR10 and cause missense mutations. The HapMap study showed that prevalence of minor allele G on the SNP of rs4129009 was $26 \%$ in Caucasian, $40 \%$ in Japanese, and 44\% in Chinese populations; A allele on the SNP of rs 11466651 was 7\% in Chinese, $17 \%$ in Japanese, and less than 5\% in Caucasian and African populations. A study of 1872 German children aged 9 to 11 years showed that the prevalence of minor allele $\mathrm{G}$ in rs4129009 was $16 \% .{ }^{37}$ A case-control study from China (318 cases with asthma and 352 non-asthmatic controls) showed that the prevalence of minor allele $\mathrm{A}$ in rs11466651 was $7 \%$ in cases and $9 \%$ in controls. ${ }^{46}$

\section{Relationship between TLR SNPs and allergic diseases}

TLR1 participates in the innate immune response to microbial agents. It cooperates with TLR2 to mediate the innate immune response to bacterial lipoproteins or lipopeptides leading to inflammatory response. A case-control study of children aged 9 to 11 years from Germany, which included 624 cases with asthma and/or bronchial hyperresponsiveness (BHR) and 1248 controls without asthma and BHR, showed that people with wild-type on 2 SNPs on TLR1 
(rs4833095, rs5743595) were protective against atopic asthma (rs4833095: odds ratio [OR] 0.59, 95\% confidence interval [CI] $0.41-0.83, P=0.003$; rs5743595: OR 0.54, $95 \%$ CI $0.37-0.81, P=0.002$ ) after adjusting for multiple comparisons. ${ }^{37}$

As noted above, TLR2 cooperates with TLR1 to mediate the innate immune response to bacterial lipoproteins or lipopeptides. A cross-sectional study of children aged 6 to 13 years from rural areas in Austria and Germany showed that children living on farms $(n=229)$ carrying a $T$ allele in rs4696480 were significantly less likely to have current hay fever symptoms, atopic sensitization, asthma, and current asthma symptoms than nonfarmers' children living in rural areas $(\mathrm{n}=380) .{ }^{41}$ In a case-control study from Korea of 440 patients with allergic rhinitis and 528 controls with no allergic symptoms and negative on allergy testing, allergic rhinitis was more common in the carriers of the $\mathrm{C}$ alleles on both rs3804099 and rs3804100 and C-C haplotype. ${ }^{38}$ In a case-control study from Norway, which included 108 allergic asthma cases and 494 controls, T allele on rs3804100 was significantly associated with allergic asthma (OR 3.40, $P=0.009$ ) and rs380409 had a nonsignificant positive association with allergic asthma. ${ }^{39}$ A large cross-sectional study of 3099 subjects from Germany showed that the minor allele of rs5743708 was significantly associated with atopy determined by skin test (OR 1.53, 95\% CI 1.06-2.19, $P=0.023$ ) and specific serum inhalative allergens (OR 1.57, 95\% CI 1.12-2.20, $P=0.009$ ) after adjusting for sex, age, and environmental tobacco smoke. ${ }^{40}$ Niebuhr et al showed that the cytokine production by monocytes from atopic dermatitis patients carrying minor allele on rs5743708 was significantly higher than those carrying wild-type ${ }^{49}$ Abhmad-Nejad et al studied 78 patients with mild to severe atopic dermatitis (AD) and found that genotypes on rs5743708 were associated with AD severity, which was measured by SCORAD. AD patients carrying a mutant allele showed higher score than those carrying no mutant allele (median 55.8 vs 44.8 ). ${ }^{50}$

In addition to the traditional SNPs on TLR2, different types of polymorphisms on TLR2 have been associated with allergic diseases and cancers. A Japanese study of 32 asthmatics by Noguchi et al showed that an insertion/deletion polymorphism in the 5 ' untranslated region of TLR2 in vitro has reduced transcriptional activity of TLR2 gene than the wild-type alleles, but none of the 16 SNPs or haplotypes of TLR2, 3, 4, and 9 were associated with IgE or asthma. ${ }^{51}$

Both TLR2 and TLR4 can recognize microbial membrane structure and have been associated with allergic diseases. A case-control study from Sweden, which included
42 patients with intermittent allergic rhinitis and 27 healthy volunteers, showed an increase in protein expression for TLR2, TLR3, and TLR4 in the nasal mucosa from the patient group and raised the possible involvement of these Toll receptors in allergic airway inflammation. ${ }^{35}$ TLR 4 has been implicated in signal transduction events induced by LPS found in most gram-negative bacteria. The two missense SNPs (rs4986790, rs4986791) have been extensively studied and associated with allergic rhinitis, airway responsiveness, and asthma. Senthilselvan et al studied 915 nonsmoking university students from Saskatchewan, Canada and found that the risk of allergic rhinitis in people carrying minor allele on both SNPs was reduced by $88 \%$ in comparison with the TLR4 wild-type group $(P=0.009)$ and atopy was associated with TLR4 polymorphism only among females. ${ }^{42}$ The same group of researchers also studied the effects of these two misssense SNPs on respiratory responses to swine barn exposure in healthy nonsmoking and nonallergic volunteers. In this study, 29 persons carrying minor allele and 29 persons carrying wild-type allele on both SNPs were exposed for 5 hours to natural swine barn environments. They found that TLR4 variants are significantly associated with reduced airway responsiveness, exhibiting a possible protective effect of TLR4 variants. ${ }^{52} \mathrm{~A}$ case-control study among Turkish children aged from 6 to 18 years, in which 613 asthmatic children cases and 327 nonasthmatic controls were included, showed that both misssense SNPs were significantly associated with atopic asthma in a Turkish population. ${ }^{43}$ Another study of the SNP rs4986790 in a Swedish population, which included 115 Swedish children aged 8 to 14 years, showed that the children in the polymorphic group were 4 times more likely to have asthma and 7 times more likely to be atopic than the wild-type group after adjusting for potential confounders. ${ }^{44}$ The authors of the Swedish paper speculate that genetic differences in populations as well as differences in gene-environment interaction might contribute to these discrepancies in the results observed between different countries.

SNPs (rs5743789, rs5743810, and rs2381289) on TLR6 contribute to the innate immune response to gram-positive bacteria and fungi leading to inflammatory response. A population based case-control study among children aged 9 to 11 years from Germany, in which 624 cases with asthma and/or BHR and 1248 controls without asthma or BHR were included, showed that people with homozygote wild-type allele (T) on rs5743789 were significantly associated with reduced risk of atopic asthma (OR $0.54,95 \%$ CI $0.37-0.79, P=0.003)$, but people with homozygote wild-type allele (C) on rs5743810 were associated with increased risk of atopic asthma (OR 1.79, 95\% CI 1.24-2.58, $P=0.002)^{37}$ 
Another case-control study from Germany, in which 200 asthma cases (68 adult, 132 children) and 212 controls were included, showed that a minor allele on rs5743810 was weakly associated (not significant after Bonferroni correction) with atopic asthma. ${ }^{45}$ A case-control study from China, which included 318 cases with asthmatics and 352 nonasthmatics as controls, showed that the T allele on rs2381289 in TLR6 was significantly associated with increased risk of allergic rhinitis among asthmatic patients (OR 1.79, 95\% CI 1.10-2.91, $P=0.025){ }^{46}$

TLR7 and TLR 8 genes are activated by single stranded RNA and have similar signaling pathways. A family study of 235 families in Demark showed that the SNPs on TLR7, rs179008, and rs2407992 were significantly associated with allergic rhinitis, asthma, atopic dermatitis, and increased specific IgE. The SNP of rs5741883 on TLR8 was also associated with allergic rhinitis among girls in a subsample of 135 families. ${ }^{47}$

The ligands to TLR9 are bacterial and viral unmethylated CpG dinucleotides. TLR9 is expressed by immune cell rich tissues, such as spleen, lymph node, bone marrow, and peripheral blood leukocytes. A study of 32 patients with seasonal allergic rhinitis and 18 healthy controls from Sweden found a widespread expression of TLR9 in epithelial cells from nasal mucosa and on all leukocytes derived from bone marrow, and concluded that TLR9 was associated with the development of allergic airway inflammation. ${ }^{53}$ Novak et al reported the results from a family study (a total of 483 parent-affected offspring trios) and a case-control study (274 atopic eczema cases and 252 controls) in Germany. In this study, a minor allele on rs5743836 was significantly associated with atopic eczema in the family study, but the association was not significant in the case-control study. ${ }^{48}$

The ligands and specific functions of TLR10 are still unknown. A case-control study from Germany, which included 624 cases with asthma and/or BHR and 1248 controls without asthma and BHR among children aged 9 to 11 years, showed that wild-type on rs4129009 in TLR10 was associated with reduced risk of atopic asthma (OR 0.58, 95\% CI 0.39-0.86, $P=0.006) .{ }^{37}$ Another case-control study from China, which included 318 asthmatic patients aged 14 to 75 years and 352 nonasthmatic controls aged 16 to 74 years, showed a protective association between the A allele on rs1 1466651 and allergic rhinitis among asthmatic patients (OR 0.49, 95\% CI $0.26-0.95, P=0.046){ }^{46}$

\section{Genomic linkage of TLRs residing regions to allergic rhinitis}

Genomic searches followed by fine mapping and positional cloning are a very useful approach for investigating possible genes related to a disease. To date, most of the research studies have been focused on asthma, and only a limited number of studies on genomic searches of genes related to allergic rhinitis have been conducted. These studies are summarized in Table 2.

A linkage analysis was carried out among 424 individuals from 100 sib-pair Danish families. ${ }^{54}$ The authors analyzed 97 polymorphic markers in 11 selected regions on chromosomes 3p, 3q, 4p, 4q, 5q, 6p, 9p, 12q, 12qter, 19q, and Xp. Allergic rhinitis was linked to the following regions: 4p15-p14 where TLR1, TLR6, and TLR10 reside; 4q32 where TLR2 resides; and Xp21-p11, which is adjacent to the region where TLR7 and TLR8 reside. In 2005, a genome screen was conducted in a sample of 295 French families with at least 1 asthmatic subject. ${ }^{55}$ They linked the following regions to allergic rhinitis: 3p24-p14 where TLR9 resides, and 9q22-q34 where TLR4 resides. A genomic linkage analysis of 250 families among a Swedish population confirmed the linkage of chromosome 9q33-q34, where TLR4 resides, to allergic rhinoconjunctivitis, which was also reported in the French study. ${ }^{56}$ The linkage of region 4q34-q35, where TLR3 resides, to allergic rhinoconjunctivitis was also reported. ${ }^{54}$

\section{Gene-environment interaction}

The associations between TLRs and allergic diseases might be modified by environmental factors. Eisenbarth et al showed in an animal model that LPS induced either Th1 - or Th2- skewed immune responses when delivered at different doses. High doses of exposure are more likely to promote Th1 responses whereas low doses of exposure promote Th2 responses. ${ }^{57}$ Kaisho et al showed that when activated by LPS, MyD88-deficient dendritic cells induce Th2-cell differentiation, whereas wild-type dendritic cells induce Th1-cell differentiation. ${ }^{58}$ The results from the two studies suggest that a low concentration of LPS exposure activates Th2-cell differentiation through MyD88 independent signaling pathway, whereas a high concentration of LPS exposure activates Th1-cell differentiation through MyD88 dependent signaling pathway. Epidemiological studies conducted in human populations have confirmed the results observed in animal models. A study of 609 children aged 6 to 13 years from rural areas in Austria and Germany showed that among farmers' children, those carrying a T allele in TLR2/-16934 were significantly less likely than children with genotype AA to have current allergic rhinitis symptoms (3\% vs $14 \%$, $P=0.01)$, diagnosis of asthma ( $3 \%$ vs $13 \%, P=0.012)$, and atopic sensitization $(14 \%$ vs $27 \%, P=0.023) .{ }^{41}$ A Swiss study of children aged from 6 to 15 years living in rural 
Table 2 Genomic linkage of chromosomal regions to allergic rhinitis

\begin{tabular}{|c|c|c|c|c|c|}
\hline \multicolumn{3}{|c|}{ Toll-like receptors (TLRs) } & \multicolumn{3}{|c|}{ Genomic studies in allergic rhinitis } \\
\hline TLRs & Chromosome & Region & Ethnic group & Family number & Region \\
\hline 1 & 4 & $\mathrm{pl} 4$ & Danish $^{54}$ & 100 & pl4-p/5 \\
\hline 2 & 4 & $\mathrm{q} 32$ & $\begin{array}{l}\text { Danish }^{54} \\
\text { (Haagerup, Børglum, } \\
\text { Binderup, \& Kruse, 2004) }\end{array}$ & 100 & $\mathrm{q} 32$ \\
\hline 3 & 4 & $\mathrm{q} 35$ & $\begin{array}{l}\text { Swedish }^{56} \\
\text { (Bu, Bradley, Söderhäll, } \\
\text { Wahlgren, Kockum, \& } \\
\text { Nordenskjöl, 2006) }\end{array}$ & 250 & q34-q35 \\
\hline 4 & 9 & q32-q33 & $\begin{array}{l}\text { Swedish }^{56} \\
\text { (Bu, Bradley, Söderhäll, } \\
\text { Wahlgren, Kockum, \& } \\
\text { Nordenskjöld, 2006) } \\
\text { French }^{55} \\
\text { (Dizier, et al 2005) }\end{array}$ & $\begin{array}{l}250 \\
295\end{array}$ & $\begin{array}{l}\text { q33-q34 } \\
q 22-q 34\end{array}$ \\
\hline 5 & I & $q 4 I-q 42$ & NA & & \\
\hline 6 & 4 & $\mathrm{pl} 4$ & $\begin{array}{l}\text { Danish }^{54} \\
\text { (Haagerup, Børglum, } \\
\text { Binderup, \& Kruse, 2004) }\end{array}$ & 100 & pl4-pl5 \\
\hline 7 & $x$ & p22 & $\begin{array}{l}\text { Danish }^{54} \\
\text { (Haagerup, Børglum, } \\
\text { Binderup, \& Kruse, 2004) }\end{array}$ & 100 & pll-p2I \\
\hline 8 & $x$ & p22 & $\begin{array}{l}\text { Danish }^{54} \\
\text { (Haagerup, Børglum, } \\
\text { Binderup, \& Kruse, 2004) }\end{array}$ & 100 & pll-p2I \\
\hline 9 & 3 & $\mathrm{p} 21.3$ & $\begin{array}{l}\text { French }^{55} \\
\text { (Dizier, et al 2005) }\end{array}$ & 295 & pl4-p24 \\
\hline 10 & 4 & $\mathrm{pl} 4$ & $\begin{array}{l}\text { Danish }^{54} \\
\text { (Haagerup, Børglum, } \\
\text { Binderup, \& Kruse, 2004) }\end{array}$ & 100 & pl4-p/5 \\
\hline
\end{tabular}

Abbreviation: NA, no report available.

communities also showed that after adjustment for potential covariates, farming as parental occupation was significantly associated with lower rates of sneezing attacks during the pollen season (adjusted OR 0.34, 95\% CI 0.12-0.89) and atopic sensitization (adjusted OR 0.31, 95\% CI 0.13-0.73). In this study, the risk of atopic sensitization was lower in children from full-time farmers (adjusted OR $0.24,95 \% \mathrm{CI}$ $0.09-0.66$ ) than from part-time farmers (adjusted OR 0.54 , $95 \%$ CI $0.15-1.96) .{ }^{59}$

\section{Treatment of allergic diseases and future perspectives}

The hygiene hypothesis enables us to connect the increasing prevalence of Th2-associated allergic diseases with reduced microorganism exposure. Microorganism exposure can help to avoid Th2-associated allergic diseases by inducing either immune deviation in favor of Th1 response or the development of Treg in response to allergens by TLRs on antigen-presenting cells, such as dendritic cells. Such associations have been demonstrated by the observed association between TLR polymorphisms and allergic diseases in many human and animal studies. However dose, type, and timing of allergen exposure play an important role in allergic sensitization.

Current therapies of allergic diseases include allergen avoidance, medications (antihistamines, leukotriene inhibitors, oral corticosteroids), and immunotherapy (achieving allergen-specific tolerance, anti-IgE). In order to achieve allergen-specific tolerance, exposure of high-dose allergen is needed to change Th2 immune response in favor of Th1, generate IL-10-producing T cells and $\mathrm{CD} 4{ }^{+} \mathrm{CD} 25^{+} \mathrm{T}$ cells, and switch B cell response in favor of IgG. Human $\mathrm{CD} 4^{+} \mathrm{CD} 25^{+} \mathrm{T}$ cells can suppress $\mathrm{T}$ cell activation due to allergen exposure; IL-10-producing T cells can also inhibit IL-4-producing T cells; and IgG can downregulate IgE-dependent Th2 lymphocyte responses. ${ }^{60}$ Treatment with corticosteroids achieves an anti-inflammatory effect for allergic diseases through increasing IL-10 production by T cells and macrophages. However, symptoms recur following treatment discontinuation. In contrast, allergen immunotherapy modulates Th2 responses 
and can persist for at least 3 to 4 years after the treatment is discontinued. ${ }^{61}$

The fact that polymorphisms of TLRs and microbial exposure in early childhood are protective against allergic diseases provides us with a new way of therapy, using well-defined bacterial products such as immunomodulators. This resulted in the development of TLR9 vaccine against allergic rhinitis. Animal models have shown inhibiting effects of Th2 cytokine responses following administration of the TLR9 ligand CpG DNA. Conjugating the allergen to $\mathrm{CpG}$ DNA dramatically enhances the immune responses to the allergen rather than administering the allergen and the CpG DNA separately (mean of AntiAmb a 1 IG1: allergen alone $=60 ;$ Amb a 1 alone $=82,269$; allergen + Amb a $1=784,852) .{ }^{62}$ In a randomized, doubleblinded, placebo-controlled phase II trial of ragweed-TLR 9 agonist vaccine for allergic rhinitis, patients with allergic rhinitis who received a 6-injection regimen of the vaccine treatment showed significant improvement over placebo on allergic symptoms during the subsequent ragweed season. ${ }^{63}$

It is vital that we improve our knowledge on genes other than TLRs that are also involved in the TLRs signaling pathway. Future studies, with particular emphasis on the gene-gene and gene-environment interaction, are very much needed. The results of these studies will hold promise for treatment of allergic rhinitis, as well as other Th2-associated allergic diseases.

\section{Discussion}

Polymorphisms of all TLRs, except TLR3 and TLR5, have been associated with allergic diseases. Six of these, TLR2, TLR4, TLR6, TLR7, TLR8, and TLR10, have been linked with allergic rhinitis as either protective or harmful factors. Polymorphisms protecting against allergic rhinitis are: $\mathrm{T}$ allele in rs4696480 of TLR2; G allele in rs4986790 and C allele in rs4986791 of TLR4; and A allele in rs11466651 of TLR10. Polymorphisms increasing the risk of allergic rhinitis are: C allele in rs3804099 and rs3804100 of TLR2; T allele in rs2381289 of TLR6; A allele in rs179008 of TLR7; G allele in rs2407992; and C allele in rs5741883 of TLR8. These observed associations were obtained from doing either linkage analysis (TLR7, TLR8) or association analysis (TLR2, TLR4, TLR6, and TLR10) in certain populations.

The polymorphisms on TLRs have been shown to influence the expression and function of TLRs and be associated with different immunity responses. Studies of direct functional effects of these SNPs showed that homozygote of A allele in rs4696480 of TLR2 was associated with increased expression of IL-6 following TLR2 stimulation. ${ }^{64}$ In comparison with homozygote of wild-type alleles after specific stimulation, homozygotes of minor allele $\mathrm{C}$ in rs5743595 of TLR1, A in rs5743789 of TLR6 and G in rs4129009 of TLR10 were associated with increased TLR1, TLR6, and TLR10 mRNA expression; higher levels of proinflammatory cytokine TNF- $\alpha$ and Th1-related cytokines IL-12 and IFN- $\gamma$; and decreased Th-2-related IL-2 expression. ${ }^{37}$

Identification of the possible genes responsible for a disease can be done in many different ways. ${ }^{65}$ Association and linkage studies are commonly used to find genes associated with a disease in large populations. The most commonly used design in association studies is the case-control, where people with a disease ('cases') and people without disease ('controls') are chosen from the population. Information on demographic and lifestyle factors and other potential confounders is usually collected retrospectively using questionnaires. Although a case-control study usually suffers from recall bias due to the differences in reporting past events between cases and controls, it is less problematic for genotype variables because these variables are less likely to change over time. Genotyping is conducted in both cases and controls for genes of interest. Selection of candidate genes is usually based on the results from other studies, where positive associations were identified, or biological functions of genes, such as genes in the signaling pathway. ${ }^{66}$ In family-based linkage studies, association between genetic markers and a disease is measured by transmission from parent to affected offspring in family pedigrees. ${ }^{67}$ If an allele is associated with a disease, then it is expected to be transmitted from parent to affected offspring more frequently. Replicating the results from several studies is required to make robust conclusions on the association between genotypes and phenotypes. ${ }^{68}$

Allergic rhinitis is associated with exposure to outdoor allergens, such as pollens (grass, trees, and weeds), indoor allergens (house dust mites, pets, and mold), and other environmental factors (air pollution, endotoxin, and bacterial/ viral infection), and exposure to livestock. ${ }^{69-71}$ However, the roles of these environmental factors in the development of allergic rhinitis are not fully understood. Predisposition to atopy involves a complex immune response process, including gene-gene and gene-environment interactions. The quantity, timing, and type of exposure influence the development of allergic diseases. Recent studies have shown that CD14 is required for recognition of 'smooth LPS' (with long O-polysaccharide chains) through TLR4 for MyD88dependent signaling pathway, and not for 'rough LPS' (without long O-polysaccharide chains). However, CD14 is required for recognition of 'rough LPS' through TLR4 
for MyD88-independent signaling pathway. ${ }^{72}$ In a mouse model, difference in the timing of LPS exposure led to totally opposite responses: protecting against sensitization if exposed early in the sensitization process; exacerbating inflammation if exposed after the sensitization process. ${ }^{73}$ Another animal model showed that a low dose of LPS exposure to mice induced Th2 response, while a high dose of LPS exposure promoted Th1 response. ${ }^{57}$ Vercelli proposed the 'endotoxin switch' hypothesis to explain the complex dose-dependent relationship of environment-gene interactions. ${ }^{74}$

The increasing prevalence of allergic diseases, including allergic rhinitis in the last 20 years, can hardly be explained by DNA sequence changes. Other inheritance mechanisms might contribute to the etiology of allergic rhinitis. Epigenetics, which studies inherited changes in phenotype caused by mechanisms other than changes in the underlying DNA sequences, has been associated with allergic diseases. Loss of DNA methylation and histone modification at the Th2 locus have been associated with overexpression of Th2-associated transcription factor GATA3 and increased expression of Th2 cytokine, IL-4, IL-5, and IL-13. ${ }^{75}$ Allergic rhinitis has a hereditary component, as shown in many studies, but does not exhibit a Mendelian hereditary pattern. This suggests the need to look into other mechanisms, such as epigenetics, which is inheritable. Shin et al reported that human T cells treated with a DNA methyltransferase inhibitor and truncation of methylation sites in the proximal regulatory regions of the STAT4 promoter showed increased expression of STAT4, a $T$ cell-specific transcription factor inducing IFN- $\gamma$ transcription. ${ }^{76}$ A study of FoxP3, a master control transcription factor for controlling Treg cells, showed decreased FoxP3 expression following methylation of a $\mathrm{CpG}$ island, and increased expression by transforming growth factor- $\beta$, which in turn decreases methylation of the $\mathrm{CpG}$ island. ${ }^{77}$ Allergic diseases including allergic rhinitis mostly show imprinting features, with an affected mother significantly more likely to transmit the disease than an affected father, ${ }^{78}$ which is compatible with epigenetic mechanisms. Hollingsworth et al showed in a mice model that in utero exposure to a diet rich in methyl donors enhanced airway hyperreactivity, lung lavage eosinophilia and IL-13, and higher serum IgE concentrations, which were trans-generationally inheritable. ${ }^{79}$ The results indicated that environmental factors, such as diet, can modify the risk of allergic airway disease through epigenetic mechanisms.

\section{Conclusions}

TLRs are an important as well as interesting group of receptors in the human genome, which can recognize a broad diversity of ligands and are involved in both innate and adaptive immune responses. Mechanisms on how TLRs interact with each other, with other genes, and with environmental factors in the development of allergic diseases are not fully understood, however. Animal model and human genetic studies over the years have confirmed the involvement of TLRs in the etiology of allergic diseases.

Looking for genes associated with allergic diseases has been the focus of numerous studies. However, general conclusions could not be made because of inconsistent results between studies and lack of replication of the results due to differences in the genetic background across ethnic groups and differences in gene-environment interactions in these studies. The chance of finding new genes associated with allergic rhinitis might be limited with the completion of the Human Genome Project. It is believed that allergic diseases are polygenic, which requires examining simultaneously several genes, with each gene contributing a small effect in the relationship with allergic diseases. This leads to a sample-size issue for many genetic association studies, as a large sample size is required to detect the small contribution of each gene, and an even larger sample is needed to test the gene-gene and gene-environment interactions.

Adequately powered studies are the key to ensuring successful replication of genetic association studies and detection of small effects of each gene, and reduce bias from misclassification of outcomes or/and genotypes. Haplotypes, which combine several SNPs, should be preferred to any single SNP because the observed association between a single SNP and outcomes may be due to the linkage disequilibrium with a nearby polymorphism, which has the true effect on the outcomes. Haplotype analysis can also help to deal with multiple comparison issues, which is inevitable in genetic association studies using large numbers of SNPs.

It is clear from our review that allergic rhinitis is influenced by both genetic predisposition and environmental exposure. However, results from epidemiological studies conducted in different populations are not consistent. This inconsistency might be related to the differences in ethnic background, and strength, route, and timing of exposure in these studies. Consideration of gene-gene and gene-environment interactions and epigenetics in future studies will provide extra insight and ultimately lead to more efficient therapeutic treatments.

\section{Acknowledgment}

Zhiwei Gao received a scholarship from the CIHR Strategic Training Program in Public Health and the Agricultural Rural Ecosystem (PHARE) and CIHR Partner Institutes, 
including the Institute of Health Services and Policy Research, Institute of Circulatory and Respiratory Health, Institute of Infection and Immunity, and Institute of Population and Public Health. Zhiwei Gao was also supported by a grant from the Canadian Institutes of Health Research (grant MOP-57907).

\section{Disclosure}

The authors disclose no conflicts of interest.

\section{References}

1. Aberg N, Sundell J, Eriksson B, Hesselmar B, Aberg B. Prevalence of allergic diseases in schoolchildren in relation to family history, upper respiratory infections, and residential characteristics. Allergy. 1996; 51(4):232-237.

2. Spector SL. Overview of comorbid associations of allergic rhinitis. J Allergy Clin Immunol. 1997;99(2):s773-s780.

3. Nathan RA, Meltzer EO, Selner JC, Storms W. Prevalence of allergic rhinitis in the United States. J Allergy Clin Immunol. 1997;99(2):s808-s812.

4. Ober C, Hoffjan S. Asthma genetics 2006: the long and winding road to gene discovery. Genes Immun. 2006;7(2):95-100.

5. Strachan DP. Hay fever, hygiene, and household size. BMJ. 1989; 299(6710):1259-1260

6. Folkerts G, Walzl G, Openshaw PJ. Do common childhood infections teach the immune system not to be allergic? Immunol Today. 2000;21(3):118-120.

7. Liu AH. Innate microbial sensors and their relevance to allergy. JAllergy Clin Immunol. 2008;122(5):846-858.

8. Peng Y, Martin DA, Kenkel J, Zhang K, Ogden CA, Elkon KB. Innate and adaptive immune response to apoptotic cells. J Autoimmun. 2007;29(4):303-309.

9. Lemaitre B, Nicolas E, Michaut L, Reichhart JM, Hoffmann JA. The dorsoventral regulatory gene cassette spatzle/Toll/cactus controls the potent antifungal response in Drosophila adults. Cell. 1996;86(6):973-983.

10. Nomura N, Miyajima N, Sazuka T, et al. Prediction of the coding sequences of unidentified human genes. I. The coding sequences of 40 new genes (KIAA0001-KIAA0040) deduced by analysis of randomly sampled cDNA clones from human immature myeloid cell line KG-1. DNA Res. 1994;1(1):27-35.

11. Kawai T, Akira S. TLR signaling. Cell Death Differ. 2006;13(5): $816-825$

12. Hasan U, Chaffois C, Gaillard C, et al. Human TLR10 Is a Functional Receptor, Expressed by B Cells and Plasmacytoid Dendritic Cells, Which Activates Gene Transcription through MyD88. J Immunol. 2005; 174(5):2942-2950.

13. Akira S, Takeda K. Toll-like receptor signalling. Nat Rev Immunol. 2004;4(7):499-511.

14. Kaisho T, Akira S. Toll-like receptor function and signaling. J Allergy Clin Immunol. 2006;117(5):979-987.

15. Hayashi F, Smith KD, Ozinsky A, et al. The innate immune response to bacterial flagellin is mediated by T-like receptor 5. Nature. 2001; 410(6832):1099-1103

16. Hemmi H, Takeuchi O, Kawai T, et al. A Toll-like receptor recognizes bacterial DNA. Nature. 2000;408(6813):740-745.

17. Alexopoulou L, Holt AC, Medzhitov R, Flavell RA. Recognition of double-stranded RNA and activation of NF-kappB by Toll-like receptor 3. Nature. 2001;413(6857):732-738.

18. Heil F, Hemmi H, Hochrein H, et al. Species-specific recognition of single-stranded RNA via Toll-like receptor 7 and 8. Science. 2004; 303(5663):1526-1529.

19. Ogura Y, Bonen DK, Inohara N, et al. A frameshift mutation in NOD2 associated with susceptibility to Crohn's disease. Nature. 2001;411(6837):603-606.
20. Inohara N, Ogura Y, Chen FF, Muto A, Nuñez G. Human NOD1 confers responsiveness to bacterial lipopolysaccharides. J Biol Chem. 2001;276(4):2551-2554.

21. Medzhitov R, Janeway C Jr. The toll receptor family and microbial recognition. Trends Microbiol. 2000;8(10):452-456.

22. Aderem A, Ulevitch RJ. Toll-like receptors in the induction of the innate immune response. Nature. 2000;406(6797):782-787.

23. Clark GJ, Angel N, Kato M, et al. The role of dendritic cells in the innate immune system. Microbes Infect. 2000;2(3):257-272.

24. O'Neill LA. Targeting signal transduction as a strategy to treat inflammatory diseases. Nat Rev Drug Discov. 2006;5(7):549-563.

25. Ozinsky A, Underhill DM, Fontenot JD, et al. The repertoire for pattern recognition of pathogens by the innate immune system is defined by cooperation between Toll-like receptors. Proc Natl Acad Sci U S A. 2000;97(25):13766-13771.

26. Bell JK, Askins J, Hall PR, Davies DR, Segal DM. The dsRNA binding site of human Toll-like receptor 3. Proc Natl Acad Sci U S A. 2006; 103(23):8792-8797.

27. Dziarski R, Gupta D. Role of MD-2 in TLR2- and TLR4-mediated recognition of Gram-negative and Gram-positive bacteria and activation of chemokine genes. J Endotoxin Res. 2000;6(5):401-405.

28. Kitchens RL. Role of CD14 in cellular recognition of bacterial lipopolysaccharides. Chem Immunol. 2000;74:61-82.

29. O'Neill LA, Bowie AG. The family of five: TIR-domain-containing adaptors in Toll-like receptor signalling. Nat Rev Immunol. 2007;7(5): 353-364.

30. Cook DN, Pisetsky DS, Schwartz DA. Toll-like receptors in the pathogenesis of human disease. Nat Immunol. 2004;5(10):975-979.

31. Lazarus R, Vercelli D, Palmer LJ, et al. Single nucleotide polymorphisms in innate immunity genes: abundant variation and potential role in complex human disease. Immunol Rev. 2002;190(1):9-25.

32. Yang IA, Holgate ST, Holloway JW. Toll-like receptor polymorphisms and allergic disease: interpreting the evidence from genetic studies. Clin Exp Allergy. 2004;34(2):163-166.

33. Sabroe I, Parker LC, Wilson AG, Whyte MK, Dower SK. Toll-like receptors: their role in allergy and non-allergic inflammatory disease. Clin Exp Allergy. 2002;32(7):984-989.

34. Månsson A, Fransson M, Adner M, et al. TLR3 in human eosinophils: functional effects and decreased expression during allergic rhinitis. Int Arch Allergy Immunol. 2010;151(2):118-128.

35. Fransson M, Adner M, Erjefalt J, Jansson L. Up-regulation of Toll-like receptors 2,3 and 4 in allergic rhinitis. Respir Res. 2005;6(1):100.

36. Lun SW, Wong CK, Ko FW, Hui DS, Lam CW. Expression and functional analysis of toll-like receptors of peripheral blood cells in asthmatic patients: implication for immunopathological mechanism in asthma. J Clin Immunol. 2009;29(3):330-342.

37. Kormann MS, Depner M, Hartl D, et al. Toll-like receptor heterodimer variants protect from childhood asthma. J Allergy Clin Immunol. 2008;122(1):86-92.

38. Kang I, Oh YK, Lee SH, Jung HM, Chae SC, Lee JH. Identification of polymorphisms in the Toll-like receptor gene and the association with allergic rhinitis. Eur Arch Otorhinolaryngol. 2010;267(3):385-389.

39. Bjørnvold M, Munthe-Kaas MC, Egeland T, et al. A TLR2 polymorphism is associated with type 1 diabetes and allergic asthma. Genes Immun. 2009;10(2):181-187.

40. Kormann MS, Ferstl R, Depner M, et al. Rare TLR2N mutations reduce TLR2 receptor function and can increase atopy risk. Allergy. 2009;64(4):636-642.

41. Eder W, Klimecki W, Yu L, et al. Toll-like receptor 2 as a major gene for asthma in children of European farmers. J Allergy Clin Immunol. 2004;113(3):482-288.

42. Senthilselvan A, Rennie D, Chenard L, et al. Association of polymorphisms of toll-like receptor 4 with a reduced prevalence of hay fever and atopy. Ann Allergy Asthma Immunol. 2008;100(5):463-468.

43. Saçkesen C, Karaaslan C, Keskin O, et al. The effect of polymorphisms at the CD14 promoter and the TLR4 gene on asthma phenotypes in Turkish children with asthma. Allergy. 2005;60(12):1485-1492. 
44. Fagerås Böttcher $M$, Hmani-Aifa $M$, Lindström A, et al. A TLR4 polymorphism is associated with asthma and reduced lipopolysaccharide-induced interleukin-12(p70) responses in Swedish children. J Allergy Clin Immunol. 2004;114(3):561-567.

45. Hoffjan S, Stemmler S, Parwez Q, et al. Evaluation of the toll-like receptor 6 Ser 249 Pro polymorphism in patients with asthma, atopic dermatitis and chronic obstructive pulmonary disease. BMC Med Genet. 2005;6:34.

46. Qian FH, Zhang Q, Zhou LF, Jin GF, Bai JL, Yin KS. Polymorphisms in the Toll-like receptor 2 subfamily and risk of asthma: a case-control analysis in a Chinese population. J Investig Allergol Clin Immunol. 2010;20(4):340-346.

47. Møller-Larsen S, Nyegaard M, Haagerup A, Vestbo J, Kruse TA, Børglum AD. Association analysis identifies TLR7 and TLR8 as novel risk genes in asthma and related disorders. Thorax. 2008;63(12):1064-1069.

48. Novak N, Yu CF, Bussmann C, et al. Putative association of a TLR9 promoter polymorphism with atopic eczema. Allergy. 2007;62(7): 766-772.

49. Niebuhr M, Langnickel J, Draing C, Renz H, Kapp A, Werfel T. Dysregulation of toll-like receptor-2 (TLR-2)-induced effects in monocytes from patients with atopic dermatitis: impact of the TLR-2 R753Q polymorphism. Allergy. 2008;63(6):728-734.

50. Ahmad-Nejad P, Mrabet-Dahbi S, Breuer K, et al. The toll-like receptor 2 R753Q polymorphism defines a subgroup of patients with atopic dermatitis having severe phenotype. J Allergy Clin Immunol. 2004;113(3): 565-567.

51. Noguchi E, Nishimura F, Fukai H, et al. An association study of asthma and total serum immunolglobin E levels for Toll-like receptor polymorphisms in a Jananese population. Clin exp Allergy. 2004;34(2):177-183.

52. Senthilselvan A, Dosman JA, Chénard L, et al. Toll-like receptor 4 variants reduce airway response in human subjects at high endotoxin levels in a swine facility. J Allergy Clin Immunol. 2009;123(5):1034-1040.

53. Fransson M, Benson M, Erjefält JS, et al. Expression of Toll-like Receptor 9 in nose, peripheral blood and bone marrow during symptomatic allergic rhinitis. Respir Res. 2007;8(1):17.

54. Haagerup A, Børglum AD, Binderup HG, Kruse TA. Fine-scale mapping of type I allergy candidate loci suggests central susceptibility genes on chromosomes 3q, 4q and Xp. Allergy. 2004;59(1):88-94.

55. Dizier MH, Bouzigon E, Guilloud-Bataille M, et al. Genome screen in the French EGEA study: detection of linked regions shared or not shared by allergic rhinitis and asthma. Genes Immun. 2005;6(2):95-102.

56. Bu LM, Bradley M, Söderhäll C, Wahlgren CF, Kockum I, Nordenskjöld $\mathrm{M}$. Genome-wide linkage analysis of allergic rhinoconjunctivitis in a Swedish population. Clin Exp Allergy. 2006;36(2):204-210.

57. Eisenbarth SC, Piggott DA, Huleatt JW, Visintin I, Herrick CA, Bottomly K. Lipopolysaccharide-enhanced, toll-like receptor 4-dependent $\mathrm{T}$ helper cell type 2 responses to inhaled antigen. $J$ Exp Med. 2002;196(12):1645-1651.

58. Kaisho T, Hoshino K, Iwabe T, Takeuchi O, Yasui T, Akira S. Endotoxin can induce MyD88-deficient dendritic cells to support T(h)2 cell differentiation. Int Immunol. 2002;14(7):695-700.

59. Braun-Fahrlander C, Gassner M, Grize L, et al. Prevalence of hay fever and allergic sensitization in farmer's children and their peers living in the same rural community. SCARPOL team. Swiss study on childhood allergy and respiratory symptoms with respect to air pollution. Clin Exp Allergy. 1999;29(1):28-34.

The Application of Clinical Genetics

\section{Publish your work in this journal}

The Application of Clinical Genetics is an international, peer-reviewed open access journal that welcomes laboratory and clinical findings in the field of human genetics. Specific topics include: Population genetics; Functional genetics; Natural history of genetic disease; Management of genetic disease; Mechanisms of genetic disease; Counselling and
60. Robinson DS, Larché M, Durham SR. Tregs and allergic disease. J Clin Invest. 2004;114(10):1389-1397.

61. Durham SR, Walker SM, Varga EM, et al. Long-term clinical efficacy of grass-pollen immunotherapy. N Engl J Med. 1999;341(7):468-475.

62. Santeliz JV, van Nest G, Traquina P, Larsen E, Wills-Karp M. Amb a 1-linked CpG oligodeoxynucleotides reverse established airway hyperreponsiveness in a murine model of asthma. J Allergy Clin Immunol. 2002;109(3):455-462.

63. Creticos PS, Schroeder JT, Hamilton RG, et al. Immunotherapy with a Ragweed-toll-like Receptor 9 agonist Vaccine for Allergic Rhinitis. N Engl J Med. 2006;355(14):1445-1455.

64. Oh DY, Schumann RR, Hamann L, Neumann K, Worm M, Heine G. Association of the toll-like receptor 2 A-16934T promoter polymorphism with severe atopic dermatitis. Allergy. 2009;64(11):1608-1615.

65. Gao PS, Huang SK. Genetic aspects of asthma. Panminerva Med. 2004;46(2):121-134.

66. Dávila I, Mullol J, Ferrer M, et al. Genetic aspects of allergic rhinitis. J Investig Allergol Clin Immunol. 2009;19 Suppl 1:25-31.

67. Clayton D, Jones H. Transmission/Disequilibrium Tests for Extended Marker Haplotypes. Am J Hum Genet. 1999;65(4):1161-1169.

68. Vercelli D, Martinez FD. The Faustian bargain of genetic association studies: bigger might not be better, or at least it might not be good enough. J Allergy Clin Immunol. 2006;117(6):1303-1305.

69. Krishna MT, Mudway I, Kelly FJ, Frew AJ, Holgate ST. Ozone, airways and allergic airways disease. Clin Exp Allergy. 1995;25(12): $1150-1158$.

70. Eder W, von Mutius E. Hygiene hypothesis and endotoxin: what is the evidence? Curr Opin Allergy Clin Immunol. 2004;4(2):113-117.

71. Senthilselvan A, Dosman JA. Risk factors for allergic rhinitis in farmers. In: McDuffie HH, Dosman JA, Semchuk KM, Olenchock SA, Senthilselvan A, editors. Agricultural Health and Safety. Boca Raton: CRC Press; 1995:75-78.

72. Jiang Z, Georgel P, Du X, et al. CD14 is required for MyD88-independent LPS signaling. Nat Immunol. 2005;6(6):565-570.

73. Tuli MK, Wale JL, Holt, PG, Sly PD. Modification of the inflammatory response to allergen challenge after exposure to bacterial lipopolysaccharide. Am J Respir Cell Mol Biol. 2000;22(5):604-612.

74. Vercelli D. Learning from discrepancies: CD14 polymorphisms, atopy and the endotoxin switch. Clin Exp Allergy. 2003;33(2):153-155.

75. van Panhuys N, le Gros G, McConnell MJ. Epigenetic regulation of Th2 cytokine expression in atopic diseases. Tissue Antigens. 2008;72(2): 91-97.

76. Shin HJ, Park HY, Jeong SJ, et al. STAT4 expression in human T cells is regulated by DNA methylation but not by promoter polymorphism. J Immunol. 2005;175(11):7143-7150.

77. Kim HP, Leonard WJ. CREB/ATF-dependent $\mathrm{T}$ cell receptor-induced FoxP3 gene expression: a role for DNA methylation. J Exp Med. 2007; 204(7):1543-1551

78. Litonjua AA, Carey VJ, Burge HA, Weiss ST, Gold DR. Parental history and the risk for childhood asthma. Does mother confer more risk than father? Am J Respir Crit Care Med. 1998;158(1):176-181.

79. Hollingsworth JW, Maruoka S, Boon K, et al. In utero supplementation with methyl donors enhances allergic airway disease in mice. $J$ Clin Invest. 2008;118(10):3462-3469.

ethical issues; Animal models; Pharmacogenetics; Prenatal diagnosis; Dysmorphology. The manuscript management system is completely online and includes a very quick and fair peer-review system, which is all easy to use. Visit http://www.dovepress.com/testimonials.php to read real quotes from published authors. 